\title{
Estudo das propriedades morfológicas, térmicas e mecânicas do compósito particulado de alumínio e polietileno de baixa densidade reciclados
}

\author{
Study of thermal, mechanical and \\ morphological properties of the \\ particulate composite aluminum/ \\ low density polyethylene
}

\author{
Fernanda Cabrera Flores Valim ${ }^{1}$, Daniel Consoli Silveira ${ }^{1}$, \\ Michelle Leali Costa ${ }^{1}$, Marcelo dos Santos Pereira ${ }^{1}$, \\ Edson Cocchieri Botelho ${ }^{1}$
}

\footnotetext{
${ }^{1}$ Departamento de Materiais e Tecnologia da Universidade Estadual Paulista (UNESP), Guaratinguetá, SP. e-mail: edson.cocchieri.botelho@gmail.com, danielsilveira.tech@gmail.com,michelle@fastline.com.br.
}

\begin{abstract}
RESUMO
Frente à crescente necessidade de recuperar o meio ambiente e seus recursos naturais, atualmente a reciclagem e reutilização dos materiais torna-se uma das soluções sustentáveis mais visadas. Neste cenário, o processamento de compósitos particulados de alumínio em matriz termoplástica de polietileno de baixa densidade (PEBD), provenientes da reciclagem de embalagens longa vida, apresenta-se de maneira atrativa para a obtenção de matéria prima para a construção civil, na fabricação de telhas de baixo peso, associado a baixo custo e elevada disponibilidade, dentre outras aplicações. Este trabalho tem por objetivo estudar as propriedades e o comportamento do compósito de polietileno de baixa densidade/alumínio reciclados. Com este objetivo, foi realizada a avaliação morfológica do compósito a partir de microscopia óptica (MO), microscopia eletrônica de varredura (MEV) e espectroscopia por energia dispersiva de raios X (EDS), bem como avaliados os comportamentos térmico e mecânico deste material após estes terem sido submetidos à climatização higrotérmica e por radiação ultravioleta (UV). Para a avaliação térmica foram empregadas técnicas de análise termogravimétrica (TGA) e calorimetria exploratória diferencial (DSC). As propriedades mecânicas foram avaliadas por análise dinâmico-mecânica (DMA) e ensaios de tração e impacto. A partir dos resultados obtidos por meio deste trabalho pode-se concluir que o intemperismo envolvendo umidade e radiação UV pode influenciar nos desempenhos térmico e mecânico do compósito de Alumínio/PEBD, porém, foi observado que esta influência não é suficiente para inviabilizar a utilização destes materiais na construção civil, garantindo este mercado para o compósito de PEBD/Al.
\end{abstract}

Palavras-chave: Reciclagem, compósito PEBD/Al, condicionamento higrotérmico e UV.

\section{ABSTRACT}

Face the growing need to restore the environment and its natural resources, currently the recycling and reuse of materials becomes one of the most important sustainable solution. In this scenario, the processing of aluminum particulate composite with low density polyethylene thermoplastic matrix (LDPE) from recycling packages, presents an attractive way to obtain raw materials for the building industry, in the manufacturing of lightweight roof tiles, associated with low cost and high availability, among other applications. This work aims to study the properties and behavior of recycled low density polyethylene/aluminum composite. In order to do this, they were performed composite morphology assessment through optical microscopy (OM), scanning electron microscopy (SEM) and energy-dispersive x-ray spectroscopy (EDS), as well as were evaluated the thermal and mechanical behavior of this material after being subjected to hygrothermal and ultraviolet conditioning (UV). For the thermal evaluation was performed thermogravimetric analysis (TGA) and differential scanning calorimetry (DSC). The mechanical properties were evaluated by dynamic mechanical analysis (DMA) and tensile and impact tests. From the results obtained from this study it can be concluded that the 
moisture involving weathering and UV radiation can influence the thermal and mechanical performance of the composite aluminum / LDPE, but it was observed that this influence was not enough to prevent the use of these materials in construction, ensuring this market for LDPE / Al composite.

Keywords: Recycling, LDPE/Al composite, hygrothermal and UV radiation conditioning.

\section{INTRODUÇÃO}

As embalagens longa vida, criadas em 1951 na Suécia e introduzidas no Brasil em 1957, tem grande aceitação no mercado, pois oferecem vantagens como criação de barreira que impede a entrada de luz, ar, água, e micro-organismos evitando, assim, a destruição de importantes vitaminas dos alimentos (Vitaminas B e C), impede também o contato do alimento com o oxigênio presente no ar, que poderia resultar em reações de oxidação e levar a deterioração do mesmo, além de permitir fácil transporte sem a necessidade de refrigeração [1]. Tais embalagens apresentam um caráter de compósito laminado, já que são formadas, principalmente, por uma combinação de 75\% em massa de papel, 20\% de PEBD e 5\% de alumínio [2]. Estas são, portanto, materiais de difícil reciclagem em função da agregação de materiais com características químicas e físicas distintas.

SANTOS [1] e NEVES [2] indicam que a reciclagem de embalagens longa vida, apesar de sua dificuldade, vem aumentando, principalmente por meio de melhorias na gestão de resíduos sólidos, como coletas seletivas, logística reversa e por meio de inovações tecnológicas [1, 2]. Ainda de acordo com a literatura o percentual de produtos reciclados pós-consumo passou de 27,1\% em 2011, para 29,2\% em 2012 e 30,3\% de toda a produção anual em 2013, totalizando para o último 72,4 mil toneladas de embalagens recicladas [3].

A primeira etapa no processo de reciclagem de embalagens longa vida ocorre na hidrapulper, onde as fibras presentes no papel serão desagregadas das demais fases, são fatores determinantes do processo o tempo de residência, tipo de rotor e a velocidade aplicada, impactando diretamente na qualidade da fibra reciclada, sendo que nesta etapa não se faz necessário o uso de aditivos químicos ou calor de processo. Ainda no hidrapulper, as fibras desagregadas serão separadas por bombeamento e o rejeito, composto de PEBD e alumínio, é segregado pela lateral do equipamento por meio de ação da gravidade. O PEBD e alumínio é então lavado, para remoção residual de fibras, prensado e secado ao ar. Enviado em fardos para recicladores de plásticos o PEBD/Al, após nova limpeza em lavador contendo um rotor, não cortante, operando acima de $1000 \mathrm{rpm}$, é centrifugado e seco [2, 4]. Na etapa adjacente, processo de aglutinação, o PEBD/Al é submetido a tratamento termomecânico para remoção de umidade, gases, além da densificação do material, resultando em boas propriedades para as etapas finais de extrusão ou injeção, seja para a produção de grânulos (pellets) ou peças acabadas.

Dentre os materiais reciclados, o papel reciclado pode ser aplicado na confecção de caixas de papelão, papel higiênico, palmilhas para sapatos, caixas de ovos, dentre outros. O material reciclado polietileno é um termoplástico e pode ser reprocessado muitas vezes sem interferência do conteúdo de alumínio durante o processo de extrusão ou injeção de peças plásticas, sendo utilizado na produção de canetas, paletes, banquetas, vassouras, coletores, dentre outros produtos. Há ainda experiências da utilização das embalagens como telhas para residências populares [5, 6].

Pequena fração do lixo constituído por tais caixas é encaminhada para a reciclagem, apenas e principalmente os $75 \%$ em massa compostos pelo papel da embalagem são reciclados, enquanto que os $20 \%$ em massa de polietileno e $5 \%$ em massa de alumínio são descartados nos aterros, tal descarte origina problemas ambientais, como a contaminação do solo, acúmulo de lixo, criação de locais de fácil proliferação de doenças, dentre outros [7].

Nesse contexto, o processamento de compósitos particulados de alumínio em matriz termoplástica de polietileno de baixa densidade, oriundos da reciclagem de embalagens longa vida, tem-se mostrado particularmente atrativo, como matéria prima para a fabricação de telhas para a construção civil. Algumas características que se destacam nesses materiais são: baixo peso, baixo custo, elevada disponibilidade de matéria prima, entre outras.

Este trabalho tem por objetivo estudar as propriedades e o comportamento do compósito de polietileno de baixa densidade/alumínio por meio do estudo da morfologia do compósito a partir de microscopias óptica (MO) e eletrônica de varredura (MEV), bem como avaliar o comportamento mecânico e térmico deste material após ser submetido aos condicionamentos higrotérmica e por radiação ultravioleta (UV). 


\section{MATERIAIS E MÉTODOS}

\subsection{Materiais}

As amostras do compósito de matriz polimérica de polietileno de baixa densidade e fase dispersa alumínio, processadas a partir de material reciclado, foram fornecidas pela empresa responsável na forma de placas com espessura de 1,9 mm e fração em massa de alumínio entre 18 e 20 \%. Estas placas foram processadas em uma extrusora de rosca simples com cinco zonas de aquecimento ( $\mathrm{L} / \mathrm{D}=30$ ) na rotação de 150 RPM. Posteriormente, os grânulos extrudados foram processados em uma injetora com a finalidade da obtenção das placas como fornecidas.

\subsection{Métodos}

A metodologia utilizada neste trabalho é apresentada na Figura 01 e cada etapa do fluxograma é detalhada a seguir.

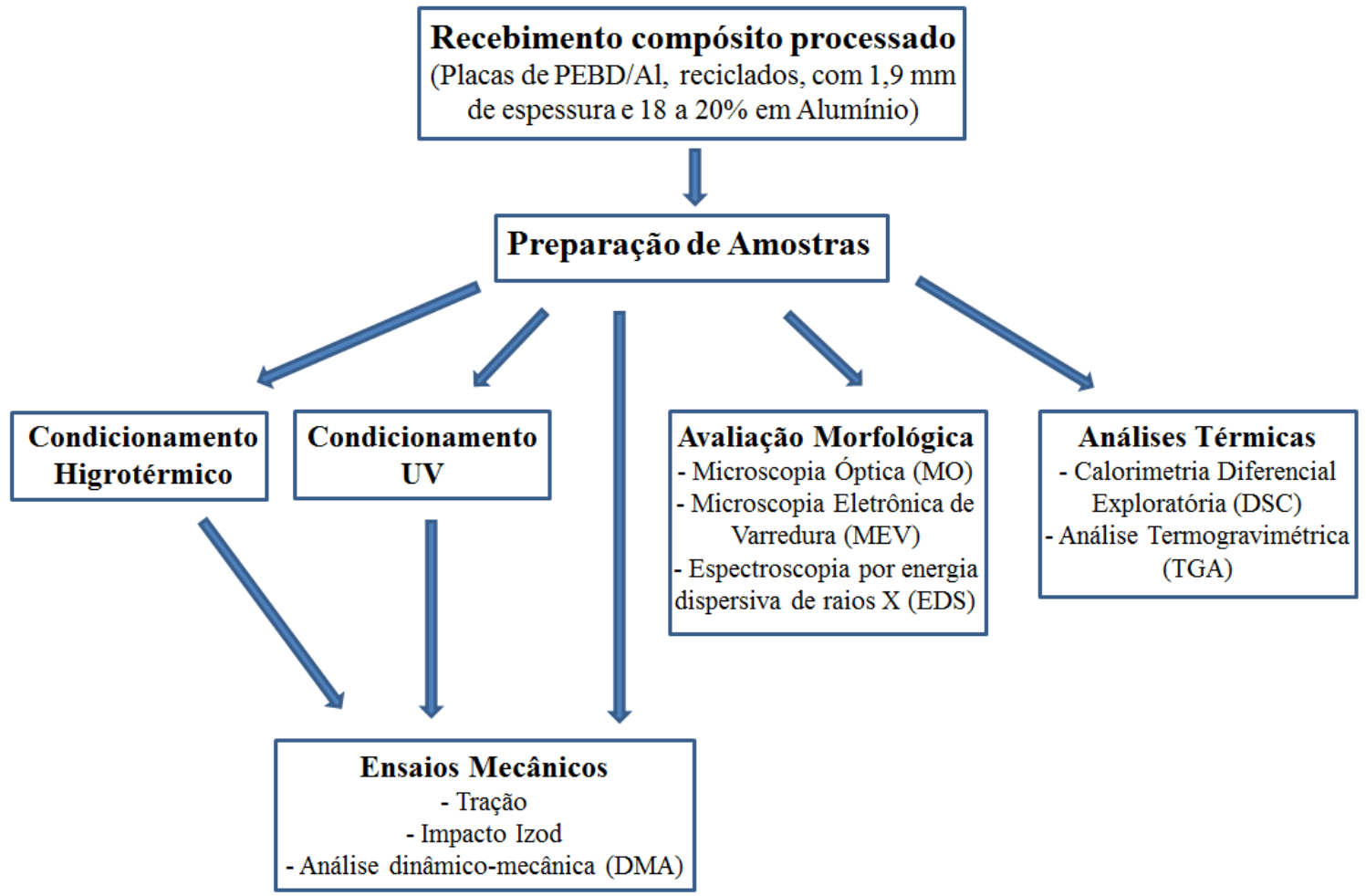

Figura 1: Metodologia utilizada no estudo do PEBD/Al.

\subsubsection{Análise Morfológica}

\subsubsection{Microscopia Óptica (MO)}

Para avaliação da qualidade dos compósitos como fornecidos para este estudo, dentre as técnicas utilizadas, inclui-se a microscopia óptica (MO). A técnica foi realizada em microscópio óptico NIKON, modelo Epihot 200. As amostras foram preparadas por meio de embutimento em resina acrílica e posterior lixamento manual em diferentes numerações de lixas (220, 320, 400, 600, 1200 e 1500), além de polimento em uma Politriz rotativa com agente abrasivo alumina de granulometria controlada de $0,3 \mu \mathrm{m}$.

\subsubsection{Microscopia Eletrônica de Varredura (MEV) e Espectroscopia por Energia Dispersiva de Raios $X(E D S)$}

Ainda visando avaliar a qualidade dos compósitos fornecidos, além de verificar a influência do processo de reciclagem na pureza do compósito, foi realizada avaliação por microscopia eletrônica de varredura (MEV) e espectroscopia por energia dispersiva de raios X (EDS) do compósito PEBD/Al. Esta avaliação foi realizada 
utilizando um microscópio da marca LEO, modelo 435 Vpi com EDX da marca Oxford e software INCA. A metodologia de preparação das amostras foi a mesma utilizada para a técnica de microscopia óptica.

\subsubsection{Condicionamento Higrotérmico}

A avaliação do processo de absorção de água pelo compósito foi realizada com a utilização de condicionamento higrotérmico conforme ASTM D5229/D5229-04. Primeiramente 15 amostras do material, nas dimensões de $60 \mathrm{~mm} \times 15 \mathrm{~mm} \times 1,9 \mathrm{~mm}$, foram secas por um período de 24 horas a uma temperatura de $60^{\circ} \mathrm{C} \mathrm{em}$ estufa a vácuo da marca Quimis e modelo Q819V2. Após o período de secagem as amostras de controle foram pesadas em uma balança analítica Mettler Toledo e, na sequência, imersas em banhos termostatizados com temperaturas de 50,70 e $80^{\circ} \mathrm{C}$. Semanalmente, três amostras de controle foram removidas do banho higrotérmico com auxílio de uma pinça, por um pequeno intervalo de tempo e o ganho de massa, devido à absorção de umidade, foi registrado. Essa operação repetiu-se por um período de, aproximadamente, 20 dias.

\subsubsection{Condicionamento UV}

Para o condicionamento ultravioleta (UV), inicialmente três amostras de dimensões $60 \mathrm{~mm}$ x $15 \mathrm{~mm}$ x 1,9 $\mathrm{mm}$ foram condicionadas por 48 horas a $60^{\circ} \mathrm{C}$ em estufa a vácuo da marca Quimis, modelo Q819V2. Posteriormente, as amostras foram submetidas em uma câmara de climatização com controle de irradiação solar, modelo QUV/spray com lâmpada de xenônio de $6500 \mathrm{~W}$, intercalando períodos de 8 horas de exposição à radiação UV e 8 horas em período de condensação.

\subsubsection{Propriedades Térmicas}

\subsubsection{Análise Termogravimétrica (TGA)}

Para esta análise uma amostra de massa inicial de 7,74 mg foi submetida a uma taxa de aquecimento de $10^{\circ} \mathrm{C} \cdot \mathrm{min}^{-1}$, sob atmosfera oxidante (ar sintético) e em uma faixa de temperatura de 30 a $980^{\circ} \mathrm{C}$. Para esta avaliação, foi utilizado um analisador térmico SII EXSTAR 6000 TG/DTA 6200.

\subsubsection{Calorimetria Exploratória Diferencial (DSC)}

A calorimetria exploratória diferencial foi realizada para a determinação das temperaturas de transição características do material, como pontos de fusão $\left(\mathrm{T}_{\mathrm{m}}\right)$ e de cristalização $\left(\mathrm{T}_{\mathrm{pc}}\right)$ do compósito PEBD/Al. A análise foi realizada em uma amostra de massa inicial $13,5 \mathrm{mg}$, taxa de aquecimento de $10^{\circ} \mathrm{C} \cdot \mathrm{min}^{-1}$ e faixa de temperatura compreendida entre 0 e $300^{\circ} \mathrm{C}$. O analisador térmico utilizado foi um SII EXSTAR 6000 DSC 6220.

\subsubsection{Propriedades Mecânicas}

\subsubsection{Análise Dinâmico-Mecânica (DMA)}

A avaliação das propriedades viscoelásticas dos laminados de PEBD/Al por meio de DMA foi realizada para amostras previamente secas, para amostras após serem submetidas aos condicionamentos higrotérmico e por radiação UV e para amostras puras (não reforçadas) de PEBD utilizadas como referência. Para esta análise foi utilizado equipamento de ensaio da TA Instruments, modelo 2980, operando em modo de varredura de frequência, sob temperatura ambiente $\left(25^{\circ} \mathrm{C}\right)$, e amplitude de $20 \mu \mathrm{m}$. O método utilizado foi por flexão em três pontos sendo que todos os ensaios foram realizados em triplicata.

\subsubsection{Ensaio de Tração}

O ensaio de resistência à tração foi executado, conforme norma ASTM D638, em 05 amostras representativas de cada condição do compósito PEBD/Al, a seco e após terem sido submetidas a condicionamentos por radiação UV e em banhos higrotérmicos. Este ensaio foi realizado em uma Máquina Universal de Ensaios Mecânicos da Marca Shimadzu Modelo AG-X, com capacidade de 50 kN.

\subsubsection{Ensaio de Impacto}

A resistência ao impacto do compósito PEBD/Al foi avaliada em um equipamento CEAST, modelo 6544/000, com pêndulo de energia de 1 Joule, conforme o método C da norma ASTM D256. Os corpos de prova foram previamente mantidos por 48 horas a $25^{\circ} \mathrm{C}$ e umidade relativa do ar de $50 \%$. Amostras submetidas aos diver- 
sos condicionamentos ambientais também foram avaliadas quanto à sua resistência ao impacto. Para este ensaio foram utilizadas 10 amostras para cada caso.

\section{RESULTADOS E DISCUSSÃO}

\subsection{Análise Morfológica}

A morfologia dos compósitos PEBD/Al observada por microscopia óptica é apresentada na Figura 02, com ampliações de 100x (Figura 02.a), 500x (Figura 02.b), 1000x (Figura 02.c) e ampliação de 200x com luz polarizada (Figura 02.d). Primeiramente, pode-se visualizar diferenciação entre as regiões correspondentes ao polietileno (regiões escuras) e o alumínio (regiões claras). Mais além, nota-se uma heterogeneidade na distribuição da fase dispersa alumínio na matriz de polietileno, além de variações do tamanho das partículas de alumínio. A análise microestrutural revela, ainda, boa interface entre o alumínio e o PEBD, bem como a tendência do alumínio em orientar-se segundo o fluxo de injeção empregado no processamento do compósito.
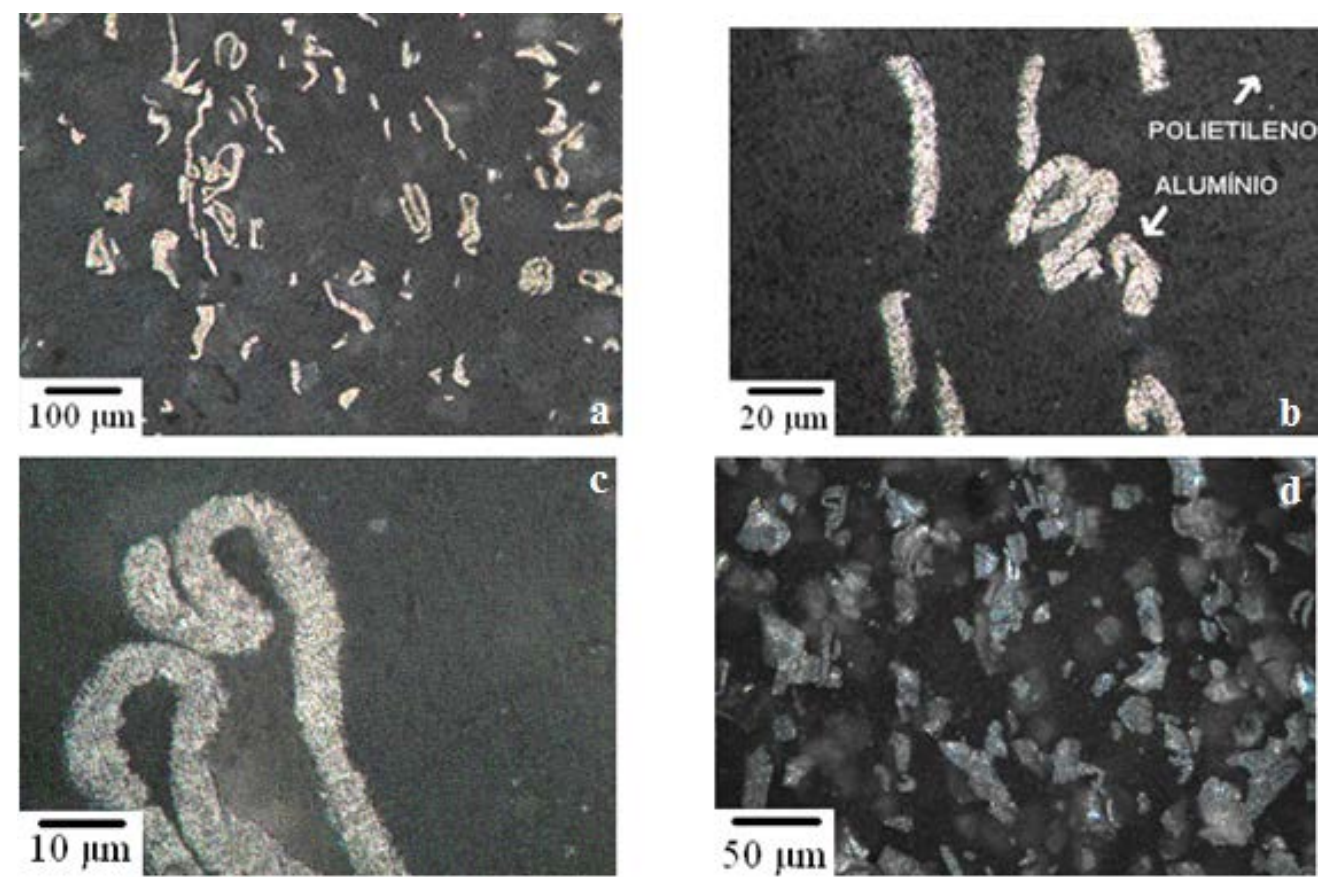

Figura 2: Análise morfológica do compósito PEBD/Al por Microscopia Óptica: a) ampliação de 100x; b) ampliação de 500x; c) ampliação de 1000x; d) ampliação de 200x com luz polarizada.

A Figura 03 é representativa da morfologia do compósito avaliado neste trabalho por meio da técnica de microscopia eletrônica de varredura. Conforme indicado pelas setas nas micrografias, pode-se observar a presença de vazios provenientes do processo de reciclagem, provavelmente oriundos do processo de extrusão devido às tensões cisalhantes entre o material, empurrado para o cabeçote da extrusora, e a superfície da mesma. Assim como evidenciado pela microscopia óptica, pode-se notar também a partir dos resultados provenientes da microscopia eletrônica de varredura a heterogeneidade na distribuição das partículas de alumínio na matriz polimérica. 

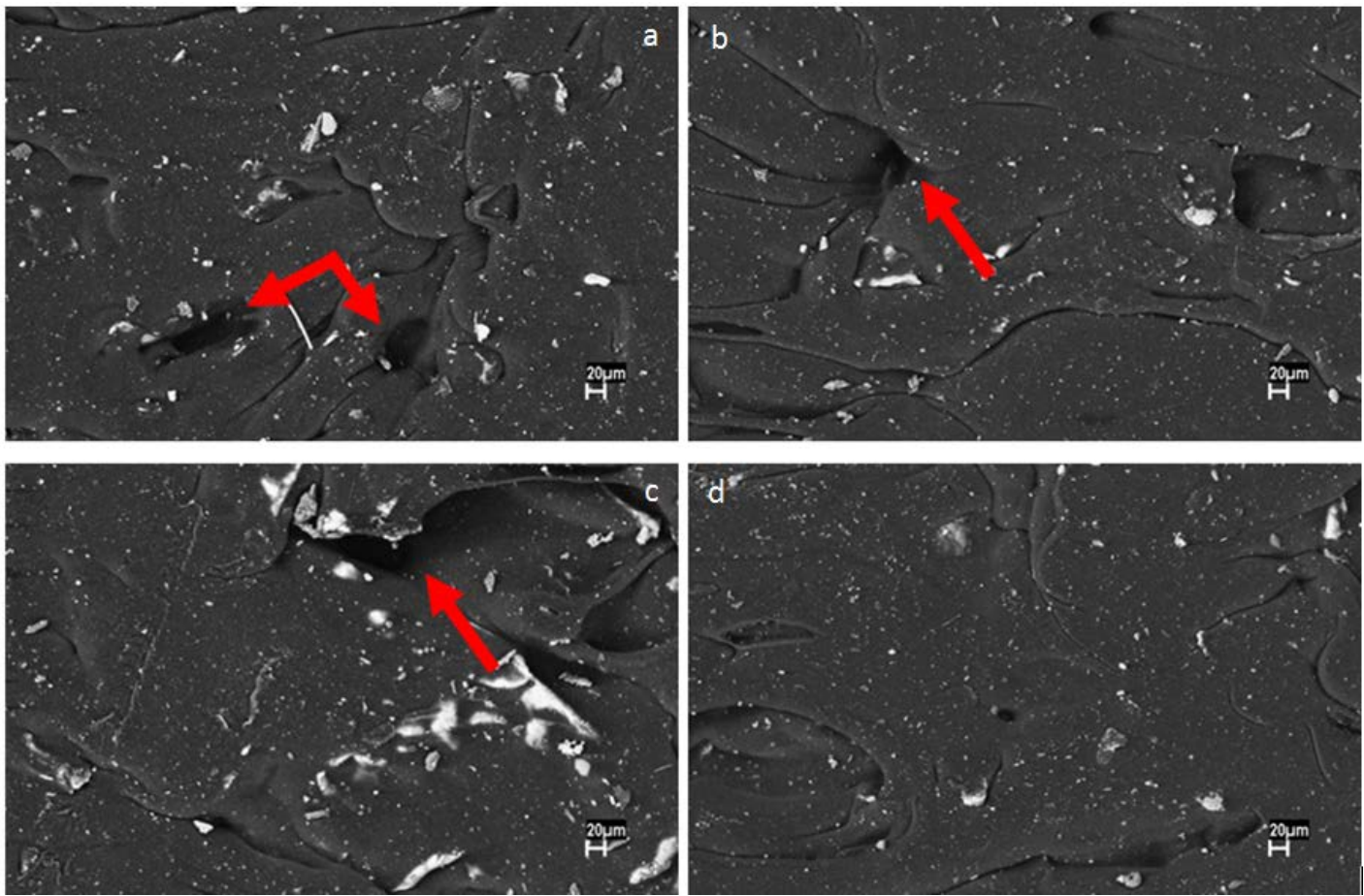

Figura 3: Microscopia Eletrônica de Varredura (MEV) do compósito PEBD/Al: a) região de varredura 01; b) região de varredura 02; c) região de varredura 03; d) região de varredura 04.

A Figura 04 apresenta a composição do compósito PEBD/Al obtida via espectroscopia por energia dispersiva de raios X (EDS), também como evidenciado na Figura 04 tal composição pode apresentar grandes variações, principalmente devido a natureza composta do material e a região onde é realizada a análise. Para regiões onde há predomínio da matriz polimérica observa-se elevado teor de carbono, conforme evidenciado pela Figura 04a, por outro lado, análises realizadas em regiões com predomínio do reforço alumínio revelam curvas conforme apresentado na Figura 04b.
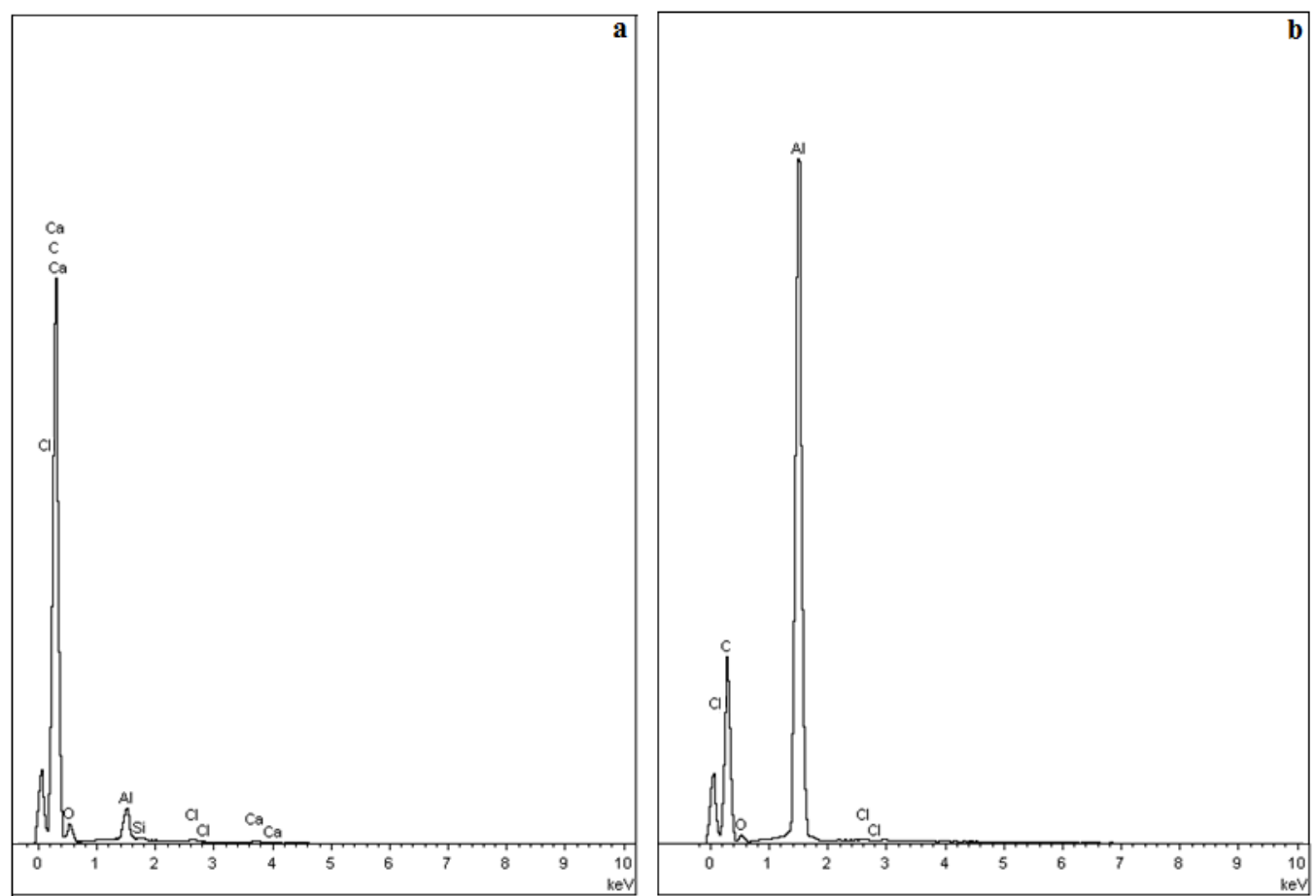

Figura 4: Curvas EDS para o compósito PEBD/Al: a) região de alta concentração de Carbono; b) região de alta concentração de Alumínio. 
Devido à inexistência de controle rigoroso para todos os parâmetros do processo de reciclagem e da origem das matérias primas torna-se inerente a presença de elementos e impurezas como cloro, cálcio, silício, dentre outros.

\subsection{Condicionamento Ambiental}

Os resultados de ganho percentual de massa para os laminados PEBD/Al em função do tempo de exposição são apresentados na Figura 05, sendo representadas as curvas para cada uma das temperaturas dos banhos termostatizados, sendo de $50^{\circ} \mathrm{C}$ (Figura 05.a), $70^{\circ} \mathrm{C}$ (Figura 05.b) e $80^{\circ} \mathrm{C}$ (Figura 05.c). Os cálculos para absorção de umidade foram realizados conforme ASTM D5229/D5229-04. As curvas mostram que nos primeiros dias de exposição a concentração de umidade nas amostras aumenta, porém, após certo tempo pode-se observar diminuição na taxa de absorção de umidade e tendência de estabilização em um percentual de ganho de massa específico para cada temperatura de banho. Conforme dados apresentados neste trabalho, o ganho médio máximo de umidade em laminados de PEBD/alumínio é de aproximadamente 8,5\% para o banho a $80^{\circ} \mathrm{C}$, com valor mínimo de $0,95 \%$ para o banho a $50^{\circ} \mathrm{C}$. Tais patamares de absorção de umidade podem levar a plasticização da matriz polimérica, resultando na diminuição do desempenho mecânico.
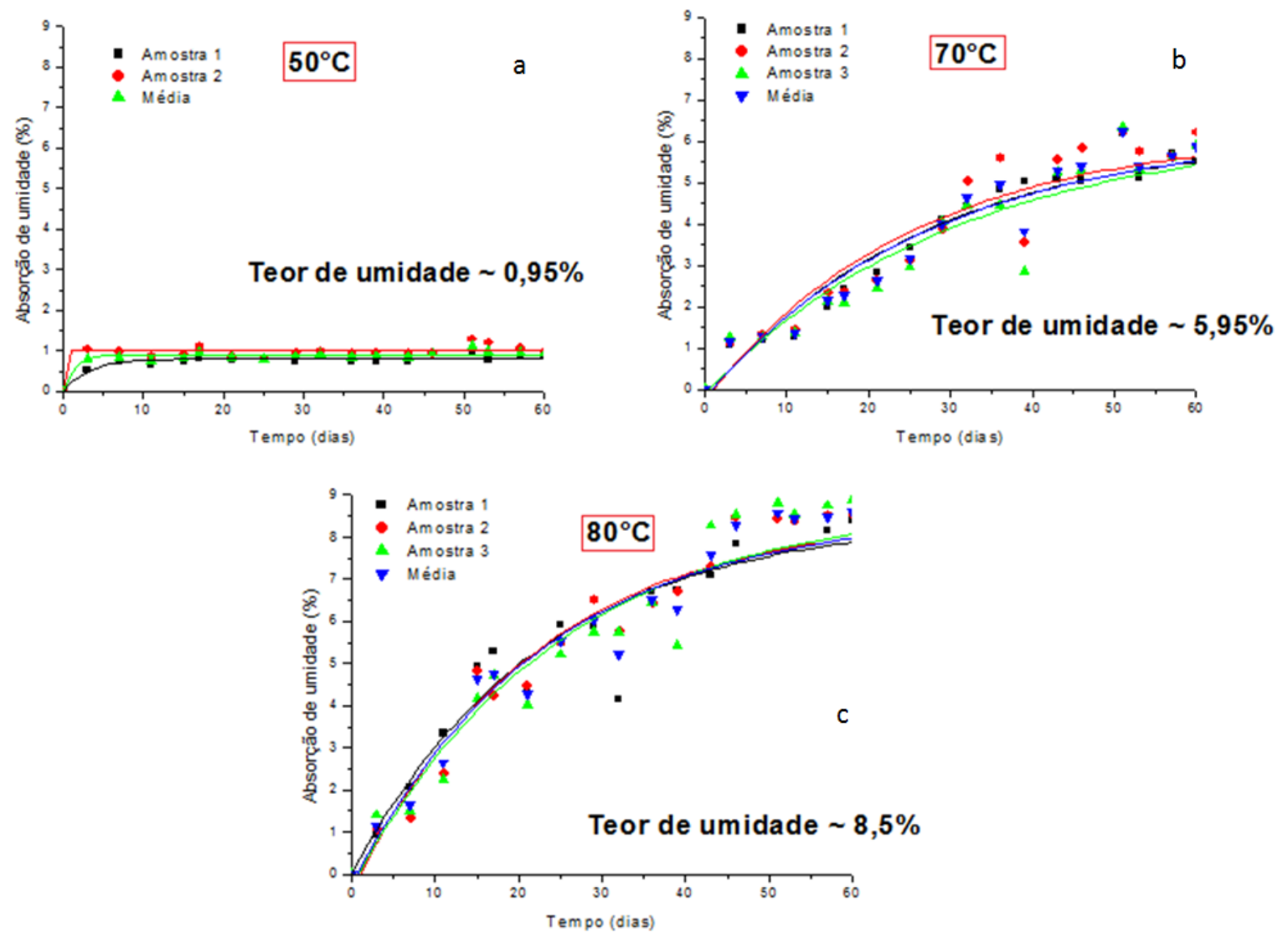

Figura 5: Absorção percentual de umidade do compósito PEBD/Al em função do tempo e da temperatura de banho: a) temperatura de banho $50^{\circ} \mathrm{C}$; b) temperatura de banho $70^{\circ} \mathrm{C}$; c) temperatura de banho $80^{\circ} \mathrm{C}$.

O mecanismo de difusão em materiais compósitos pode ser considerado como resultado do movimento aleatório de moléculas promovido pelos gradientes de temperatura e pressão. A fim de se avaliar o comportamento Fickiano, pode-se utilizar as curvas de absorção de umidade em função do tempo de condicionamento, tal como representado pela equação $1[8,9,10]$.

$$
M_{g} / M_{\infty}=k t^{n}
$$

Onde $M g$ é o ganho de massa em relação ao tempo; $M \infty$ é o ganho de massa na condição de equilíbrio e $k$ e $n$, constantes. Para os sistemas de comportamento Fickiano, o valor de $n$ deve estar perto de 0,5, nesse 
caso quem controla o mecanismo de difusão é a diferença de concentração. A Tabela 01 apresenta os resultados de difusividade e expoente de difusão obtido para o compósito PEBD/Al.

Tabela 1: Difusividade e expoente de difusão do material.

\begin{tabular}{l|l|l}
\hline TEMPERATURA $\left({ }^{\circ} \mathbf{C}\right)$ & DIFUSIVIDADE $\left(\mathbf{c m}^{2} / \mathbf{m i n}\right)$ & EXPOENTE DE DIFUSÃO $(\mathbf{n})$ \\
\hline 50 & $0,59 \times 10^{-6}$ & 1,00 \\
\hline 70 & $4,62 \times 10^{-6}$ & 0,90 \\
\hline 80 & $5,03 \times 10^{-6}$ & 0,80 \\
\hline
\end{tabular}

Os dados da Tabela 01 comprovam a proporcionalidade direta entre difusividade e temperatura do banho, além de apresentar valores de $n$ superiores a 0,5 e tendendo a 1,0, para os quais o transporte ocorre de forma anômala e o mecanismo é controlado pela relaxação das cadeias e pela concentração.

Já para o condicionamento UV, a Figura 06 apresenta a ocorrência de um comportamento linear de perda de massa, tal perda pode ser explicada pelo mecanismo de degradação do polietileno de baixa densidade, no qual a absorção de radiação UV por impurezas do polímero inicia uma sequência de reações químicas foto-oxidativas originando grupos químicos carbonila e hidroperóxidos, que por sua vez contribuem para o processo de reticulação e cisão de cadeias, consequentemente levando a degradação fotoquímica do material [24]. Apesar do condicionamento ter sido realizado intercalando períodos de 8 horas sob radiação UV e 8 horas de condensação, a despeito da condensação promover ganho de massa nas amostras pela retenção de umidade, predomina a degradação por UV.

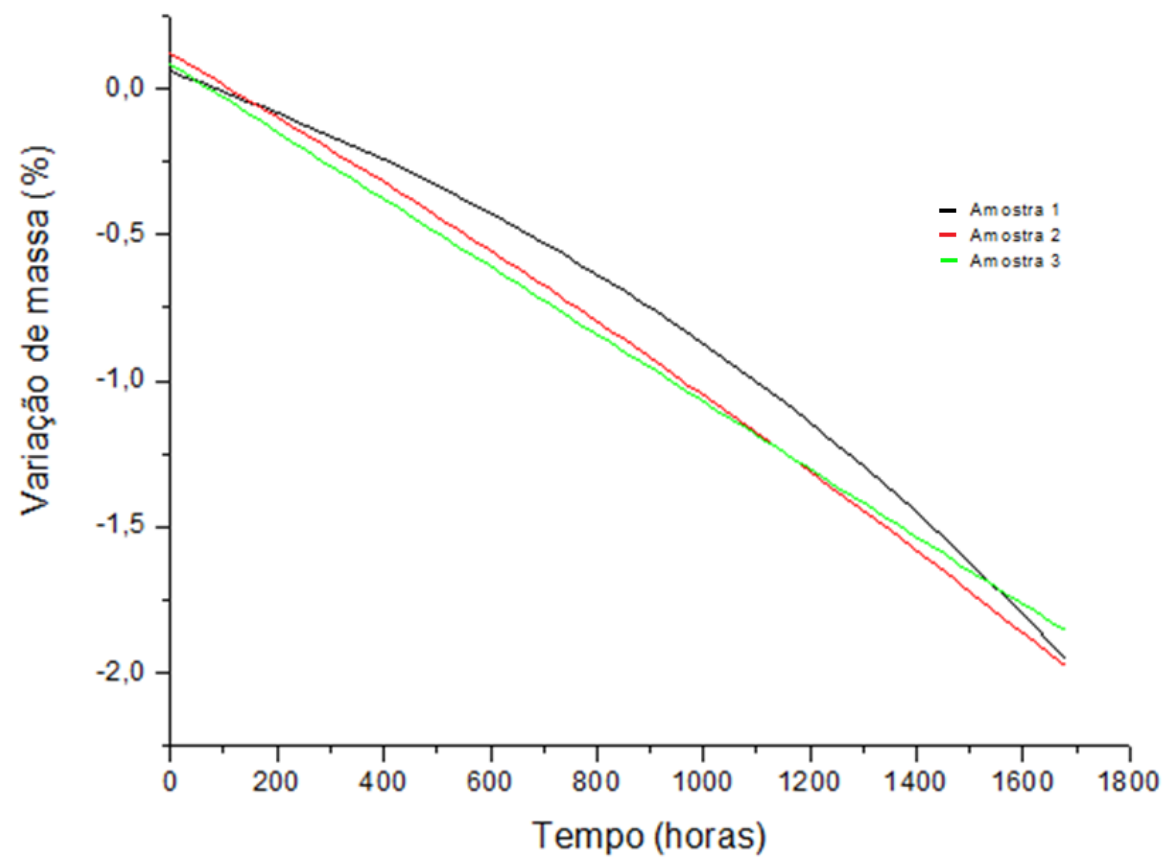

Figura 6: Perda de massa em função do condicionamento UV para três amostras avaliadas nas mesmas condições.

\subsection{Propriedades Térmicas}

A Figura 07a apresenta a curva de análise termogravimétrica (TGA) para o compósito $\mathrm{PEBD} / \mathrm{Al}$, entre $190^{\circ} \mathrm{C}$ e $400^{\circ} \mathrm{C}$. A partir deste resultado pode ser observado que o compósito sofre degradação térmica resultando na perda de aproximadamente 7,9\% em massa, provavelmente referente à perda de água e frações de baixo peso molecular. Entre 400 e $490^{\circ} \mathrm{C}$ pode ser observada uma segunda perda de massa devido à degradação das cadeias poliméricas, resultando, após ambas, um resíduo de carbono fixo e alumínio de 17\%. A Figura 07.b apresenta a curva termogravimétrica derivada (DTG), evidenciando uma temperatura média $\left(T_{50 \%}\right)$ de $420^{\circ} \mathrm{C}$, ponto onde ocorre a maior taxa de degradação do material. 

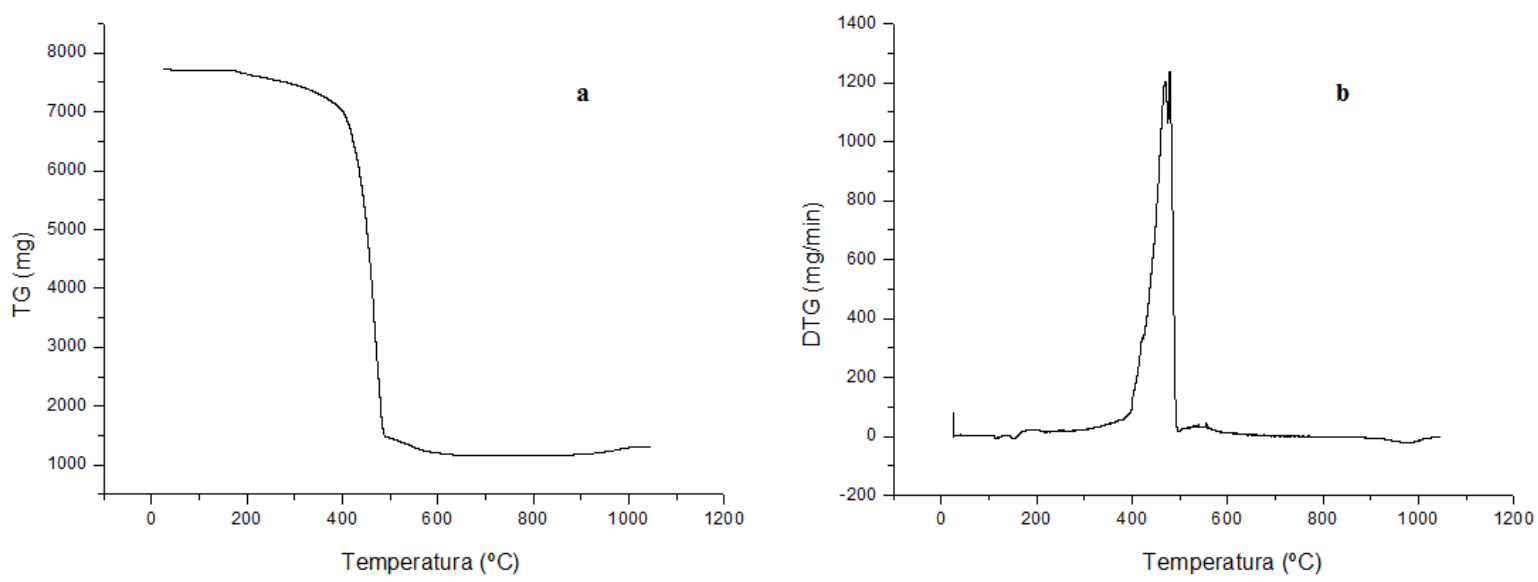

Figura 7: Curvas de análise termogravimétrica: a) TGA compósito PEBD/Al; b) DTG compósito PEBD/Al.

Os pontos de fusão, cristalização e de início de degradação do compósito foram determinados por meio da técnica de calorimetria exploratória diferencial (DSC). A Figura 08 apresenta a curva de fluxo de calor em relação à temperatura para um primeiro aquecimento seguido de resfriamento. Verifica-se, a partir da curva de aquecimento, um pico endotérmico de aproximadamente $107^{\circ} \mathrm{C}$ e referente à temperatura de fusão (Tf), além de um pico exotérmico indicando a temperatura de degradação térmica do material de aproximadamente $230^{\circ} \mathrm{C}$. Por sua vez, a curva de resfriamento apresenta um pico exotérmico referente à cristalização do material e equivalente a $90^{\circ} \mathrm{C}(\mathrm{Tpc})$.

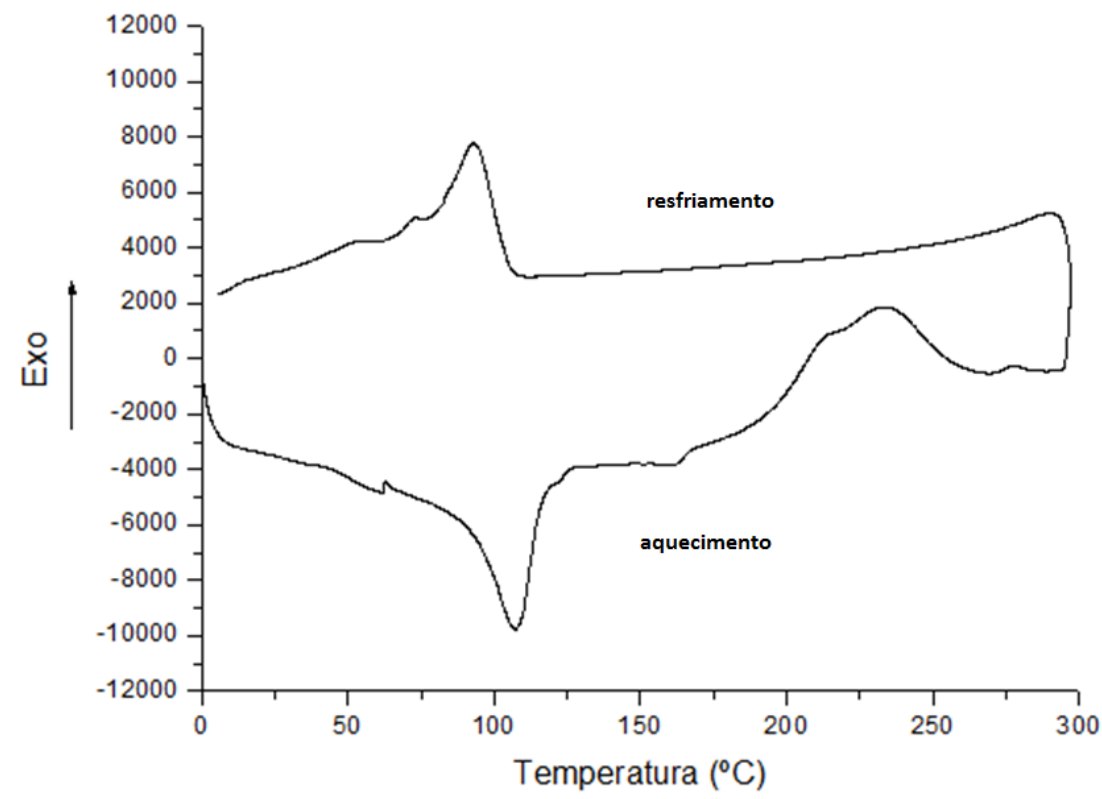

Figura 8: Curvas de aquecimento e resfriamento durante DSC do compósito PEBD/Al.

\subsection{Propriedades Mecânicas}

Amostras dos laminados de PEBD/Al não climatizadas (a seco) e após climatização higrotérmica em banhos termostatizados de 50,70 e $80^{\circ} \mathrm{C}$ foram avaliadas quanto as suas propriedades mecânicas por meio de análise dinâmico-mecânica (DMA). O objetivo principal foi avaliar os platôs elásticos e viscosos, não se preocupando com a análise da temperatura de transição vítrea do material, uma vez que esta ocorre em temperaturas abaixo das condições ambientes e operacionais do material. A Figura 9 apresenta curvas representativas do DMA para o compósito PEBD/Al. A análise da curva revela um aumento do módulo de perda (E”) com o aumento da frequência de $0,5 \mathrm{~Hz}$ até $8 \mathrm{~Hz}$. Porém, com o aumento da frequência o módulo de armazenamento (E') e o $\tan \delta$ apresentam, respectivamente, aumentos e quedas contínuas. Tal comportamento é caracterís- 
tico para o material avaliado neste trabalho, seja para o PEBD seco, úmido ou amostras referência de PEBD, e pode ser explicado pela relaxação das cadeias poliméricas.

Figura 9: Curva de DMA para uma amostra de PEBD/Al após condicionamento higrotérmico a $50{ }^{\circ} \mathrm{C}$.

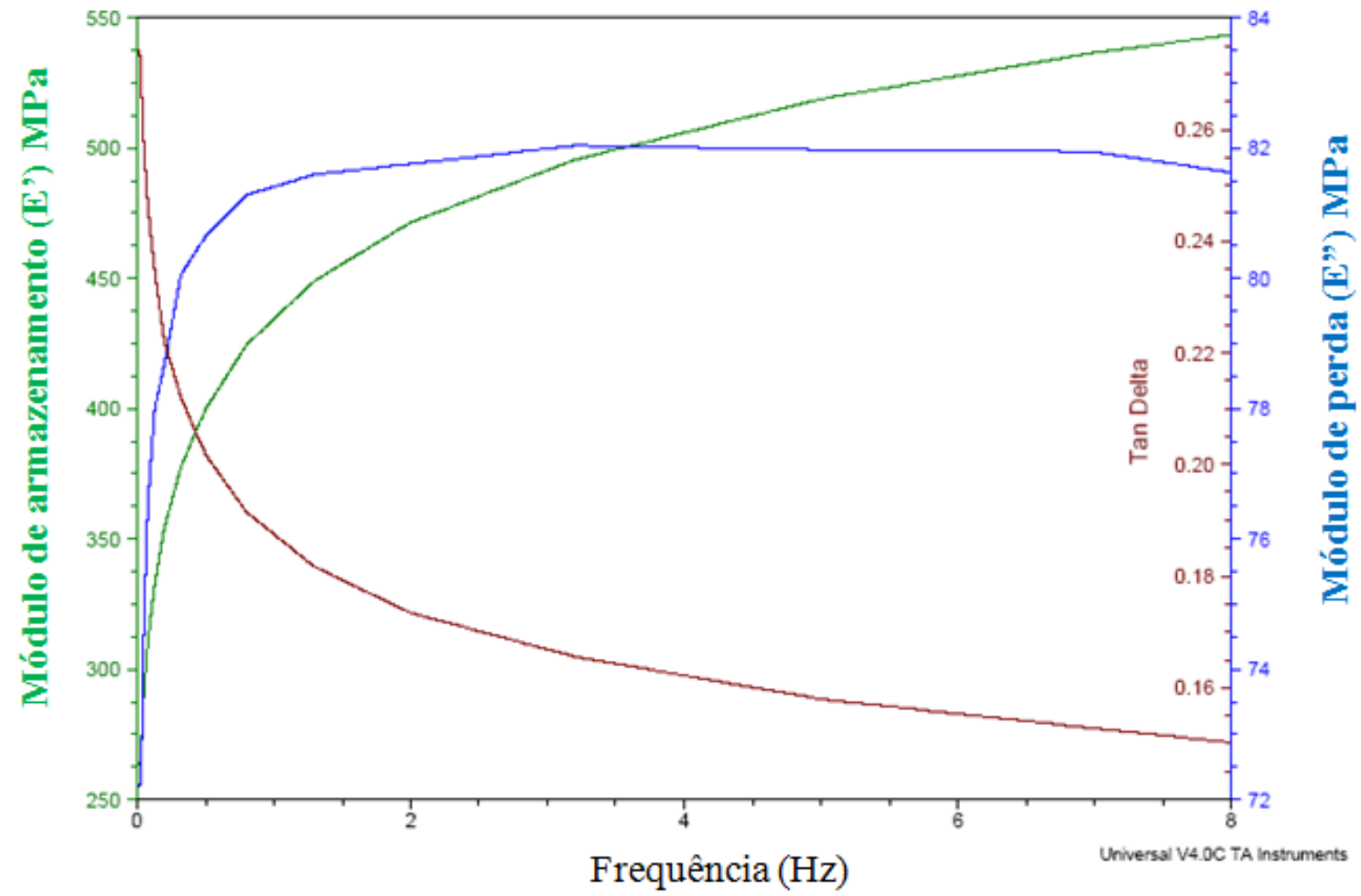

Os resultados viscoelásticos para as amostras submetidas ao condicionamento higrotérmico, quando avaliados a $8 \mathrm{~Hz}$, por períodos de 15 e 30 dias são apresentados nas Tabelas 02 e 03.

Tabela 2: Resultados do DMA para amostras submetidas ao condicionamento higrotérmico por período de 15 dias.

\begin{tabular}{l|l|l|l}
\hline AMOSTRA & TAN DELTA & E” (MPa) & E' (MPa) \\
\hline a seco & 0,14 & 50,5 & 350 \\
\hline $50^{\circ} \mathrm{C}$ & 0,15 & 80,8 & 540 \\
\hline $70^{\circ} \mathrm{C}$ & 0,13 & 58,4 & 450 \\
\hline $80^{\circ} \mathrm{C}$ & 0,13 & 62,8 & 480 \\
\hline
\end{tabular}

Tabela 3: Resultados do DMA para amostras submetidas ao condicionamento higrotérmico por período de 30 dias.

\begin{tabular}{l|l|l|l}
\hline AMOSTRA & TAN DELTA & E” (MPa) & E' (MPa) \\
\hline a seco & 0,13 & 88,5 & 680 \\
\hline $50^{\circ} \mathrm{C}$ & 0,13 & 104,2 & 800 \\
\hline $70^{\circ} \mathrm{C}$ & 0,10 & 91,0 & 880 \\
\hline $80^{\circ} \mathrm{C}$ & 0,13 & 88,5 & 680 \\
\hline
\end{tabular}

Como apresentado nas tabelas, as amostras submetidas ao condicionamento higrotérmico a $50^{\circ} \mathrm{C}$ por período de 15 dias apresentaram os valores mais elevados para tan $\delta$, tal comportamento pode ser explicado por um possível processo de reticulação da matriz polimérica. Todavia, quando submetidas a condicionamentos higrotérmicos com temperaturas mais elevadas, além do processo de reticulação, ocorre uma maior taxa 
de absorção de umidade como comprovado pelas curvas de absorção de umidade anteriormente apresentadas, podendo levar a plasticização da matriz polimérica e ocasionando uma queda no desempenho viscoelástico. Ainda, a partir das Tabelas 02 e 03 pode-se verificar que as amostras condicionadas a 70 e $80^{\circ} \mathrm{C}$ apresentaram desempenho viscoelástico similares, sendo que pequenas divergências entre os valores de E” e E’ podem estar relacionados a eventuais diferenças de distribuição do reforço alumínio na matriz de PEBD, como comprovado pela avaliação morfológica dos compósitos.

Valores para o limite de resistência ao impacto para os laminados de PEBD/Al não climatizados, após climatização higrotérmica e após climatização UV são apresentados na Tabela 04.

Tabela 4: Resultados para limite de resistência ao impacto do PEBD/Al seco, condicionado higrotermicamente e condicionado em UV.

\begin{tabular}{l|l|l}
\hline AMOSTRA & LIMITE DE RESISTÊNCIA AO IMPACTO $(\mathbf{J} / \mathbf{m})$ & DESVIO PADRÃO \\
\hline PEBD/Al - seco & 109 & 15,4 \\
\hline PEBD/Al - úmido & 89 & 9,8 \\
\hline PEBD/Al - UV & 78 & 6,2 \\
\hline
\end{tabular}

Comparativamente ao compósito PEBD/Al não climatizado (seco), o compósito condicionado higrotermicamente (úmido) apresentou uma redução de $19 \%$ na tenacidade, enquanto que ao ser comparado ao compósito condicionado por UV a redução foi de $28 \%$. Desta forma, pode-se concluir que ocorre uma queda na resistência ao impacto do material quando submetido aos processos de intemperismo, sendo maior a redução da tenacidade do material pela exposição à radiação UV, entretanto, esta diminuição pode ser considerada menor quando os valores de desvios-padrão são apresentados. Pode-se explicar tal fato pela alteração e degradação das cadeias poliméricas da matriz do compósito quando submetido aos referidos condicionamentos. Além disso, associado ao processo de sorção de umidade da matriz polimérica, outros mecanismos devem ser levados em consideração tais como a capilaridade e o transporte através de microtrincas e vazios. $\mathrm{O}$ mecanismo de capilaridade envolve o fluxo de água ao longo da interface livre/matriz seguido pela difusão através da interface da matriz polimérica. O transporte de umidade por meio de microtrincas envolve tanto o fluxo como o armazenamento de água nos vazios e em outras formas de microdefeitos. Como o fluxo de água é proporcional ao gradiente de concentração, amostras expostas a ambientes com maiores teores de umidade podem apresentar maiores valores de absorção de umidade. Dependendo do caso, esta difusão pode ainda gerar a entrada de umidade para regiões de volume livre, muitas vezes, resultando em um processo de inchamento da matriz polimérica. Entretanto, considerando as aplicações na indústria civil, esta pequena diminuição nas propriedades mecânicas a partir do impacto do intemperismo analisado neste trabalho não é suficiente para invalidar estas aplicações.

A Tabela 05 apresenta os resultados provenientes do ensaio mecânico de tração para o material compósito condicionado e não condicionado.

Tabela 5: Resultados para limite de resistência a tração do PEBD/Al seco, condicionado higrotermicamente e condicionado em UV.

\begin{tabular}{l|l|l|l}
\hline AMOSTRA & FORÇA MÁXIMA (N) & TENSÃo MÁXIMA (N/mm $\left.{ }^{2}\right)$ & DEFORMAÇÃO MÁXIMA (\%) \\
\hline PEBD/Al - seco & 234,6 & 9,09 & 4,56 \\
\hline PEBD/Al - úmido & 190,8 & 6,96 & 3,87 \\
\hline PEBD/Al - UV & 185,6 & 6,69 & 3,65 \\
\hline
\end{tabular}

A partir destes resultados pode ser observado que houve uma perda de resistência a tração de 19,0\% para o compósito PEBD/Al climatizado por umidade e temperatura e de 21,0\% para o material condicionado em UV, resultado similar ao constatado a partir dos ensaios de impacto. Da mesma forma como analisado para os resultados de impacto, quando avaliado os desvios-padrões esta diferença é reduzida. Esta redução ocorre para todos os parâmetros levantados no ensaio, ou seja: resistência máxima, tensão máxima e deformação máxima. Neste ensaio o intemperismo também influenciou nas propriedades mecânicas do material compósito deste estudo, evidenciando uma possível degradação da cadeia polimérica da matriz devido a exposição à temperatura, umidade e radiação UV. Porém, novamente considerando a aplicação que vem apre- 
sentada neste artigo (indústria civil), esta variação pode ser considerada aceitável para a utilização deste material para telhas. A partir dos resultados disponíveis na Tabela 05 deve-se salientar que o compósito que sofre menor deformação é também o que apresentou maior degradação (Condicionamento UV), uma vez que o material apresenta um comportamento mais próximo ao frágil conforme é maior a quantidade de macro cadeias poliméricas rompidas durante o condicionamento por radiação UV. De acordo com as considerações encontradas na literatura de CÂNDIDO [25], COSTA [26] e MAYER [27], a umidade absorvida nos compósitos de matriz polimérica pode reduzir a resistência mecânica e a rigidez do laminado, decorrentes do efeito da plasticização da matriz com o enfraquecimento da interface fase dispersa/matriz. Essas reduções nas propriedades mecânicas são particularmente significativas em temperaturas elevadas. Assim, a presença de umidade no compósito pode causar mudanças significativas nas características físico-químicas da matriz. Em um compósito estrutural decréscimos no módulo de elasticidade e redução na temperatura de transição vítrea são evidências do mecanismo de plasticização da matriz [25, 26, 27]. Nesse caso, quando se deseja utilizar as propriedades do material por um longo período de tempo torna-se necessário considerar a ação desse mecanismo de degradação da matriz polimérica.

\section{CONCLUSÕES}

As análises morfológicas em distintas regiões do material compósito deste trabalho permite concluir que dispersões heterogêneas do reforço particulado alumínio em matriz de PEBD podem influenciar significativamente nas propriedades mecânicas e físico-químicas do material processado. Ainda, as avaliações via MEV e por EDS revelaram a presença de vazios originados durante o processo de reciclagem do material, mais especificamente da etapa de extrusão.

Por meio das avaliações pós condicionamento higrotérmico, pode-se concluir que as amostras submetidas as temperaturas mais elevadas tiveram maior taxa de absorção de umidade, com taxa máxima de absorção de $8,5 \%$ após 60 dias em banho termostatizado a $80^{\circ} \mathrm{C}$. Com base nas Leis de Fick para a difusão e nos valores do expoente $n$ obtidos superiores a 0,5 , pode-se concluir que o mecanismo de difusão no compósito PEBD/Al apresenta comportamento não fickiano e anômalo, dependendo da diferença de concentração bem como da relaxação a nível molecular.

Resultados obtidos por meio de análises dinâmico-mecânicas (DMA) comprovam, para o material condicionado higrotermicamente a $50^{\circ} \mathrm{C}$ e período de 15 dias, a ocorrência do aumento da reticulação das cadeias poliméricas da matriz PEBD do compósito $\mathrm{PEBD} / \mathrm{Al}$, além da plasticização da matriz polimérica para as amostras condicionadas a 70 e $80^{\circ} \mathrm{C}$, temperaturas onde a difusão e absorção de umidade são superiores.

Após o condicionamento por radiação UV do material compósito PEBD/Al observa-se que a perda de massa do compósito, ocorre de forma linear, perda esta possivelmente decorrente da quebra das cadeias poliméricas.

O condicionamento UV mostrou-se ainda mais severo que o condicionamento higrotérmico quanto a redução das propriedades mecânicas de resistência ao impacto e tração do compósito $\mathrm{PEBD/Al}$, uma vez que o índice de degradação da matriz polimérica foi maior pelo efeito da radiação UV. Sendo assim, as perdas de propriedades mecânicas são agravadas pela climatização por radiação UV, causando maiores quebras de ligações das cadeias poliméricas e tornando o compósito PEBD/Al mais frágil e suportando menores deformações. Entretanto, considerando uma faixa de segurança de $20 \%$, assim como os respectivos desvios-padrões, mesmo após este compósito ter sido submetido aos condicionamentos ambientais por radiação UV e em banhos termostatizados, os resultados mecânicos se encontraram em uma faixa aceitável para aplicações não estruturais na indústria civil.

\section{AGRADECIMENTOS}

Os autores agradecem a Fundação de Amparo à Pesquisa do Estado de São Paulo (FAPESP) e ao CNPq pelo apoio financeiro prestados neste trabalho.

\section{BIBLIOGRAFIA}

[1] SANTOS, C. F. M., "Gestão Ambiental nas Empresas: O caso da Indústria de Embalagens Tetra Pak”, ENEGEP - Encontro Nacional de Engenharia de Produção, Rio de Janeiro, 1999.

[2] NEVES, F. L., “A Reciclagem de Embalagens Cartonadas Tetra Pak”, Associação Brasileira de Resíduos Sólidos e Limpeza Pública, 1999. 
[3] Relatório de Sustentabilidade 2012/2013. TETRA PAK®. Disponível em:

$<$ http://www.tetrapak.com/br/MediaBank/Relatorio_Sustentabilidade_Tetra\%20Pak_2012\%202013pdf.pdf>. Acesso em: 01 mai 2015.

[4] ZUBEN, F. V., NEVES, F. L., "Recycling of Aluminum and Polyethylene from Tetra Pak Carton Packages as Plastic Composite”, GPEC 2003 - Global Pastics Environmental Concil, Detroit, Michigan, February, 26-27, 2003.

[5] PEREIRA, R. D. A., PAVANELLI, G., SOUZA, M. T. S., "Um Estudo dos Canais Reversos em uma Empresa de Embalagens Cartonadas”, ENEGEP - Encontro Nacional de Engenharia de Produção, Rio de Janeiro, Brasil, 13 a 16 de outubro de 2008.

[6] SCHMUTZLER, L.O.F. Projeto Forro Vida longa UNICAMP. Disponível em: $<$ http://www.fem.unicamp.br/ vidalong/projleite.html>. Acesso em: 21 jan 2015.

[7] NEVES, F. L. Novos Desenvolvimentos para Reciclagem de Embalagens Longa Vida, 2005.

[8] CHUNG, K., SEREFIS, J. C., NAM, J. D., "Investigation of Thermal Degradation Behavior of Polymeric Composites: Prediction of Thermal Cycling Effect From Isothermal Data”, Composites: Part A, v. 31, pp. 945-957, 2000.

[9] DUTTA, I., "Role of Interfacial and Matrix Creep During Thermal Cycling of Continuous Fiber Reinforced Metal - Matrix Composites”, Acta mater, v. 48, pp. 1055-1074, 2000.

[10] FRENOT, M. C. L., ROUQUIE, S., "Influence of Oxidative Environments on Damage in C/Epoxy Laminates Subjected to Thermal Cycling”, Composites Science and Technology, v. 64, pp. 1725-1735, 2004.

[11] BROWN, M. E., Introduction to Thermal Analysis, 1st ed., New York, Chapman and Hall, 1988.

[12] CANEVAROLO Jr, S. V., Técnicas de Caracterização de Polímeros, 1ª ed., São Paulo, Artliber, 2004.

[13] CASSU, S. N., FELISBERTI, M. I., “Comportamento Dinâmico-Mecânico e Relaxações em Polímeros e Blendas Poliméricas”, Química Nova, v. 28, n. 2, Mar/Abr 2005.

[14] CERQUEIRA, M. (2003) "Placas e Telhas produzidas a partir de Polietileno/Alumínio presentes nas embalagens Tetra Pak”, Coletânea de Artigos Técnicos, Tetra Pak.

[15] COSTA, M. L. Efeito do Conteúdo de Vazios no Comportamento Mecânico de Compósitos Avançados Carbono/Epóxi e Carbono/Bismaleimida, Instituto Tecnológico de Aeronáutica, São José dos Campos, 2002.

[16] COUTINHO, F. M. B., MELLO, I. L., MARIA, L. C. D. S., "Polietileno: principais tipos, propriedades e aplicações”, Polímeros, São Carlos, v. 13, n. 1, Março 2003.

[17] ] MALISKA, A. M. Microscopia eletrônica de varredura e microanálise. Santa Catarina: UFSC. Disponível em: <http://www.materiais.ufsc.br/lcm/web_MEV/MEV_Apostila.pdf>. Acesso em: 21 jan 2015. [18] MANO, E. B., Polímeros como Materiais de Engenharia, 1ª ed., São Paulo, Edgard Blucher, 2001.

[19] MARTINS, M. A. P., ARAÚJO, H. N., PELLIZZARO, M. "Estudo de Compósitos com Produtos de Reciclagem”, In: XXXI Simpósio Brasileiro de Pesquisa Operacional, Juiz de Fora, 2009.

[20] VIEIRA, R. A., NONO, M. C. A., MATTOS, M. L. B., "MEV and EDS investigations of the Ti film-steel substrate interface”, Acta Microscopica, Supplement A, v. B, pp.309-310, 1999.

[21] ASTM INTERNACIONAL, ASTM D 5229/D5229 (2004), Standard Test Method for Moisture Absorption Properties and Equilibrium Conditioning of Polymer Matrix Composite Materials, Procedimento B, West Conshohocken, PA, EUA, 2005.

[22] ASTM INTERNACIONAL, ASTM D638 - 10, Standard Test Method for Tensile Properties of Plastics, West Conshohocken, PA, EUA, 2010.

[23] ASTM INTERNACIONAL, ASTM D256 - 10, Standard Test Methods for Determining the Izod Pendulum Impact Resistance of Plastics, West Conshohocken, PA, EUA, 2010.

[24] FECHINE, G. J. M., SANTOS, J. A. B., RABELLO, M. S. “Avaliação da fotodegradação de poliolefinas através de exposição natural e artificial”, Química Nova, v. 29, n. 4, pp. 674-680, 2006.

[25] CÂNDIDO, G. M. Influência do Condicionamento Ambiental na Resistência à Delaminação de Borda Livre em Compósitos Avançados. Tese de Doutorado, Instituto Tecnológico de Aeronáutica (ITA), São José dos Campos, 2001.

[26] COSTA, M. L. Efeito do conteúdo de vazios no comportamento mecânico de compósitos avançados carbono/epóxi e carbono/bismaleimida., Tese de D.Sc., Instituto Tecnológico de Aeronáutica (ITA), São José dos Campos, 2002. 
VALIM, F. C.; SILVEIRA, D. C.; COSTA, M. L. revista Matéria, v.20, n.4, pp. 852 - 865, 2015.

[27] MAYER, S. Influência do Condicionamento Ambiental na Resistência à Tração de Laminados de Compósitos Poliméricos Reparados, Dissertação de M.Sc., Instituto Tecnológico de Aeronáutica (ITA), São José dos Campos, 2003. 